\title{
Solving Problem Types Contextualized to the Quadratic Function and Error Analysis: A Case Study
}

\author{
Verónica Díaz ${ }^{1 *}$, Maria Aravena ${ }^{2}$, George Flores $^{3}$ \\ 1 Universidad de Los Lagos, Departamento de Ciencias Exactas, Osorno, CHILE \\ 2 Universidad Católica del Maule, Facultad de Ciencias Básicas, Talca, CHILE \\ 3 Universidad de Los Lagos, Dirección de Acceso, Equidad y Permanencia, Osorno, CHILE
}

Received 8 August 2020 - Accepted 28 August 2020

\begin{abstract}
The article aims to determine the academic performance and errors in the resolution of types of problems of application of the quadratic function, of high school students from the Los Lagos Region and Los Rios Region in Chile. The approach is qualitative and descriptive with case studies. A math test with open response problems and an opinion questionnaire were developed and applied. Through the results, the highest academic performance is evidenced in the routine problems of purely mathematical context and fantasist context, but with difficulty in the resolution of non-routine problems. In addition, errors originating in affective and emotional attitudes associated with blockages at the time of initiating the resolution, forgetfulness at the time of posing the quadratic function, prevail over cognitive errors originating in an obstacle and errors originating in the absence of meaning.
\end{abstract}

Keywords: errors, problem solving, quadratic function, secondary education

\section{INTRODUCTION}

In the unit of Algebra and Functions of Secondary Education in Chile, students begin with the recognition of functions and their distinction with relationships in diverse contexts. In this unit, it is possible to identify topics related to types of functions, particularly the quadratic function whose teaching and learning is linked to the second year of secondary education, according to the Ministry of Education in Chile (MINEDUC).

This research, carried out with types of problems according to nature and context, and the classification of errors according to their origin committed by students when they solve problems of application of the quadratic function, allows us to have an assessment instrument that in the future will allow us to continue analyzing why students make mistakes and how they affect affective mastery in mathematics work in general and in problem solving in particular of Education in Chile (MINEDUC, 2019). However, there are gaps in the actual level of their education, depending on the type of educational establishment, which may be municipal, privately subsidized, or privately paid (Díaz \& Poblete, 2018). On the other hand, there is agreement in recent research regarding the difficulty that students have in learning quadratic function (Celik \& Güzel, 2019; Ruli, Pradawanto \& Mulyana, 2019), which has its origin not only in the cognitive domain, but also in the affective domain. Some research in the cognitive domain has been proposed to relate to records of semiotic representations and technological environments (Bajaña, 2019; Esquer, Robles, Cosmes, \& Ansaldo 2017; Farez, 2018; GomezBlancarte, Guirette, \& Morales-Colorado, 2017; Özaltun \& Bukova, 2019; Peralta-García, Encinas-Pablos, \& Cuevas-Salazar, 2019). Studies of quadratic function and problem solving are less common.

In the affective domain, it is also rare to find studies of a student's affections and problem solving. However, there are several studies on the relationship between the teacher's attitude and the academic performance of students in mathematics (Beilock, Schaeffer, \& Rozek, 2017; Chapman, 2013; Fulgar, 2020; Good \& Lavigne, 2018; Haciomeroglu, 2013). The importance of attitudes on student performance in mathematics has also been investigated (Langat, 2015; Peteros, Columna, Etcuban, Almerino, \& Almerino, 2019) concluding that attitudes towards mathematics have a significant impact on student performance. 


\section{Contribution to the literature}

- The study contributes to the literature in Mathematics Education on solving problem types according nature and context in secondary education, by providing empirical evidence of student when apply knowledge of the quadratic function.

- The study identified three different types of errors, which were influenced by the different educational establishments students' prior experiences in problem solving routine and non-routine.

- This research, allows us to have an assessment instrument that in the future will allow to continue analyzing why students make mistakes and how they affect affective mastery in mathematics work in general and in problem solving in particular.

For Blanco, Caballero and Guerrero (2013) the linkage between emotions and performance in mathematics becomes visible in the student, when he or she needs to understand the structure or needs to recover the information of a specific mathematical task, at the moments when he or she designs a strategy to solve a problem that requires the memory of formulas or routine procedures, or in the processes of self-regulation of his or her learning linked to a methodology of teaching mathematics that rejects (Díaz, Belmar, \& Poblete, 2018). All these situations generate errors and/or difficulties that constitute obstacles in the learning of mathematics. At present, emphasis is placed on the need to develop skills for problem solving and the development of creative abilities in mathematics (Díaz \& Poblete, 2018), but also on the need to recognize and anticipate errors that are part of the productions of most students, constituting a stable element in the processes of teaching and learning mathematics at all levels of the education system. In general, the wrong concepts are presented through errors. An error might be an error, a calculation error or a wrong judgement, and such category underlines non-systematic errors (Díaz, 2019).

The curricular bases of MINEDUC (2019), for secondary education students, recurrently propose as a central objective, to build student learning based on skills and content. Specifically, they point out the importance of going deeper into routine and non-routine problems as a key learning opportunity in mathematics. To do so, the student must be able to solve problems, make decisions, apply, and build mathematical models on which to base decisions. However, results in international assessments such as PISA and TIMSS (OECD, 2019) in which Chile has participated, show that these objectives have not been completely achieved.

Problem solving since the mid-twentieth century has been the focus of much international research, but also of major difficulties associated with it (Hernández, Castañeda, \& Gonzalez, 2019), which are evident from the mistakes that students make when solving problems. In this context, the research objective arises.

\section{Aims of the Research}

The aim of research objective was to determine the academic performance and errors in the resolution of types of problems of application of the quadratic function, in third year students of the Los Lagos and Los Rios regions in Chile. This study was guided by the next research question: What type of errors prevail in solving problems contextualized to the quadratic function?

\section{THEORETICAL FRAMEWORK}

Because mathematical problem solving plays such a critical role in the curriculum, it is imperative that students gain mastery of this complex process. Recurrent research at different latitudes, however, indicates that students have difficulty in this skill (Fuadi, Minarni, \& Banjarnahor, 2017; Peranginangin, 2017) which is reflected in performance on standardized achievement tests.

On the other hand, for decades the pedagogy of Mathematics Education has been based mainly on teachers demonstrating problems from correctly worked examples, as models for students to replicate while practicing their own problems (Rushton, 2018). There is consensus that problem solving is also a powerful and effective tool for learning (Boesen, Lithner, \& Palm, 2010; Davis, Smith, Roy, \& Bilgic, 2014; Henderson, 2012; Jäder, Lithner, \& Sidenvall, 2019; Schoenfeld, 2012), as well as a central component of mathematical reasoning (MINEDUC, 2019) that requires higher level thinking skills and therefore needs the incorporation of routine and non-routine problems for the student. The best use of this skill is achieved when the student is able to solve problems in a wide range of subjects in science, technology, business, finance, medicine and everyday life (Akyüz, 2020) and in diverse contexts that allow applications of mathematical objects.

\section{Types of Problems}

For this work, as a theoretical framework, the types of problems that the authors Díaz and Poblete (2001) have been working on in different areas of mathematics were taken. According to this classification, problems are considered according to their nature and context. According to their nature, problems are classified into: routine and non-routine ones and according to their context: they are classified as real, realistic, fantastical and purely mathematical (Figure 1). 


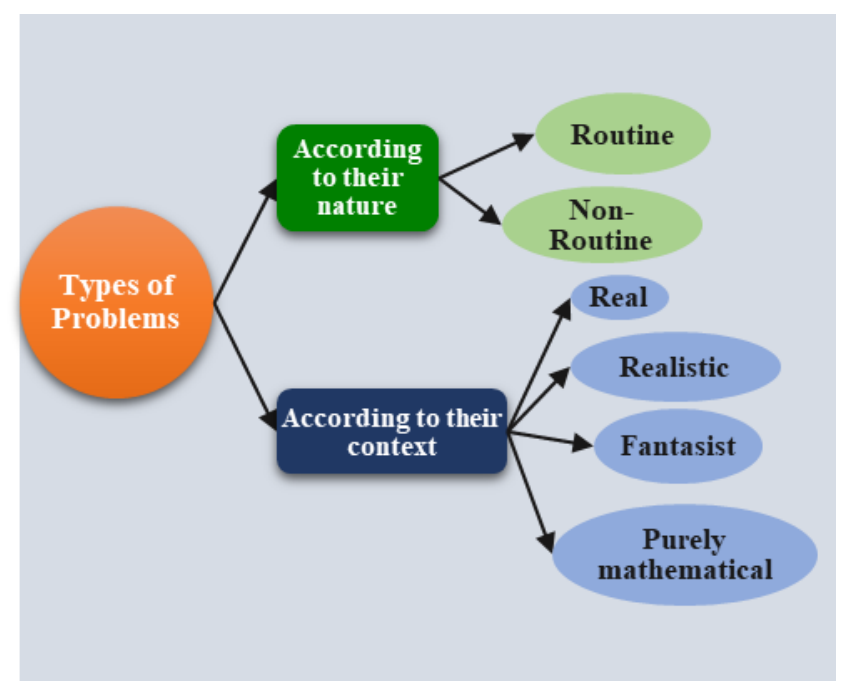

Figure 1. Types of problems

\section{Nature of the problem}

Based on their nature, problems are defined as Routine and Non-Routine ones.

Routine problems are like those solved during instructional courses; the student follows a sequence that involves understanding the concepts and algorithms to achieve valid solutions.

A problem will be Non-Routine when a student does not know an answer or a previously established procedure or routine to find it.

\section{Context of the problem}

- Real context problem: A context is real if it is produced in reality and compromises the actions of the student in it.

- Realistic context problem: A context is realistic if it is susceptible to be produced. It is about a simulation of reality or a part of it.

- Fantasist context problem: A context is fantasist if it is fruit of imagination and is unfounded in reality.

- Purely mathematical context: A context is purely mathematical if makes exclusive reference to mathematical objects: numbers, relations and arithmetic operations, geometric figures, etc.

\section{Quadratic Function}

One area of recurrent difficulty is algebra, which is linked to functions, in that they model a dependent relationship between one quantity and another (Díaz \& Poblete, 2018). For National Council of Teachers of Mathematics NCTM (2020) together, algebra and functions constitute the language of generalization that allows the systematic representation of patterns and relationships between numbers and objects, analysing change and modelling real-world situations (NCTM, 2018). However, there are many questions about learning quadratic functions that remain unanswered. The concept of quadratic function is one of the most important ideas in school mathematics since graphs and equations are important parts of mathematics (Benning \& Agyei, 2016; Nielsen, 2015; Parent, 2015). The idea of quadratic function plays a key role in the development of mathematical concepts, since it crosses a range of mathematical content domains, including algebra and geometry (NCTM, 2020).

On the other hand, mathematics teachers' understanding of quadratic functions is critical to students' success in mathematics, and there seems to be agreement that, for many high school students, solving and understanding quadratic functions can be conceptually challenging because of the need to make connections between various representations of the function, as well as the connections between the various ways in which the quadratic equation can be expressed (Didis, Bas, \& Erbas, 2011; Kilic, 2011).

Research on quadratic functions of teaching and learning (Didis et al., 2011; Ellis \& Grinstead, 2008; Eraslan, 2008; Metcalf, 2007; Strickland, 2011) has involved students after their learning of specific functions. One such quadratic function study was conducted (Metcalf, 2007) with three undergraduate students at a university of New England. He found that one of his participants could perform several procedures but showed limited relational understanding of the concepts. Unfortunately, none of his participants showed much flexibility in moving between representations. In addition, all exhibited communication difficulties in relation to quadratic function.

Although it is not limited to these examples, quadratic functions are related to mathematical thinking and reasoning in the real world due, for example, to their involvement in the description of the path of projectiles, appearing on suspension bridges, as cross sections of car headlights, satellite dishes and radio telescopes, to describe the orbits along which the planets move and the link between quadratic equations and acceleration (Budd \& Sangwin, 2004).

Kotsopoulos (2007) points out three forms of the quadratic function which are the standard form, the factored form, and the vertex form. Students become confused when the concepts of quadratic function are presented in different ways to which they are not accustomed. Mutambara, Tendere and Chagwiza (2020) conducted an exploration of teachers' understanding of the concept of quadratic function. The findings of the study revealed that most pre-service teachers appeared to be operating at the level of understanding action, with very few teachers having reached the object level. The researchers Martínez-Planell, Torres, and Hernandez (2015) indicated that students who knew some rules related to the resolution of quadratic functions could 
apply these rules without thinking about why they did it, or if what they were doing was mathematically correct.

Recent studies have shown that students and teachers in service present a diversity of difficulties related to quadratic function. Obstacles that in the processes of teaching and learning are potentially generating errors. Authors such as Radatz (1980), Rico (1995), Socas (1997) and others, have established error classifications in mathematics.

\section{Types of Errors}

Since errors are inherent to human life, their presence in the acquisition and development of knowledge in mathematics is a constant throughout the history of the discipline. In recent years, incorrect problems have been introduced for the analysis of errors by students (McLaren, Adams, \& Mayer, 2015). For Rushton (2018) error analysis carryings out are aligned with standards of mathematical practice (NCTM, 2014) and mathematical teaching practices (NCTM, 2014). Researchers report a result of increased mathematical understanding when these practices are used with a combination of problems worked on correctly and incorrectly (Adams et al., 2014; Durkin \& Rittle-Johnson, 2012; Große \& Renkl, 2007; Loibl \& Rummel, 2014; McLaren et al., 2012; NCTM, 2014; NGA Center \& CCSSO, 2010; Sisman \& Aksu, 2015).

The MINEDUC (2019) recognizes that mistakes provide opportunities for learning in mathematics. Authors such as Oser and Spychiger (2005), Heinze and Reiss (2007) suggest that errors are necessary to develop the individual's idea of what is false and what is correct. But how often do students see their mistakes as signs of failure? How many students, as well as parents or guardians, believe that the goal of learning math is to get only the right answer? Teachers often resist the idea of using error analysis in their classrooms. Some believe that analyzing them takes too long (Tsovaltzi, Melis, McLaren, Meyer, Dietrich, \& Goguadze, 2010). According to error analysis is an instructional strategy that helps students retain their learning. But prior to that, it is fundamental to know the types of errors that students can make when solving a mathematical problem.

For the purposes of the theoretical framework of this research, the classification of errors proposed by Socas (1997) is considered, which, associating the cognitive and affective domains, recognizes three categories: errors that have their origin in an obstacle, in the absence of meaning, and errors that have their origin in affective and emotional attitudes, which are presented below.

- Errors that have their origin in an obstacle: The obstacle is considered as an acquired knowledge, not as a lack of knowledge, which was effective in some specific context but when the student uses that knowledge in another context, it results in inadequate responses.

- Errors that have their origin in the absence of meaning: These can be divided into three classes:

(1) Errors that have their origin in arithmetic, because of not having assimilated relationships and processes in an arithmetic context,

(2) Procedural errors, i.e. when students use formulas, definitions, or rules inappropriately,

(3) Errors due to misinterpretation of mathematical language.

- Errors that have their origin in affective and emotional attitudes: These errors derive from lack of concentration, blockages, forgetfulness, etc.

For many students and teachers, mistakes are associated with negative feelings. According to the American Psychological Association, feelings that affect a person's mood and emotional reaction can be called affection, and the attitude toward mathematics is an example of an affective state (Berger, Mackenzie, \& Holmes, 2020).

For Fulgar (2020) attitude in general, it refers to a person's way of thinking, acting, and behaving. It has a truly relevant implication for the student, the teacher, the immediate social group, and the whole school system (Mensah, Okyere, \& Kuranchie, 2013). Attitudes can affect behaviour that influences what the student selects from the environment, how he or she will react to teachers, to the material being used and to other students.

When students are approached with non-routine math problems, according to (Díaz, Belmar, \& Poblete, 2018), their reactions often include a lot of emotion and if the problem-solving time is long, the emotional responses can even be very intense.

\section{METHODOLOGY}

This study corresponds to a qualitative descriptive research with case studies (Hernández, Fernández, \& Baptista, 2014), with the purpose of studying in a detailed, comprehensive and in-depth way, the academic performance and the errors presented by the students in the resolution of types of application problems on quadratic function.

Three educational establishments are included, in order to have representative case studies of the three types of educational establishments that exist in the country. Five third-year secondary school students are analysed, selected based on student availability and, five educational establishments in the Los Lagos and Los Ríos Regions to which they belong. The students are hereinafter referred to by the word case and are listed from 1 to 5 . 


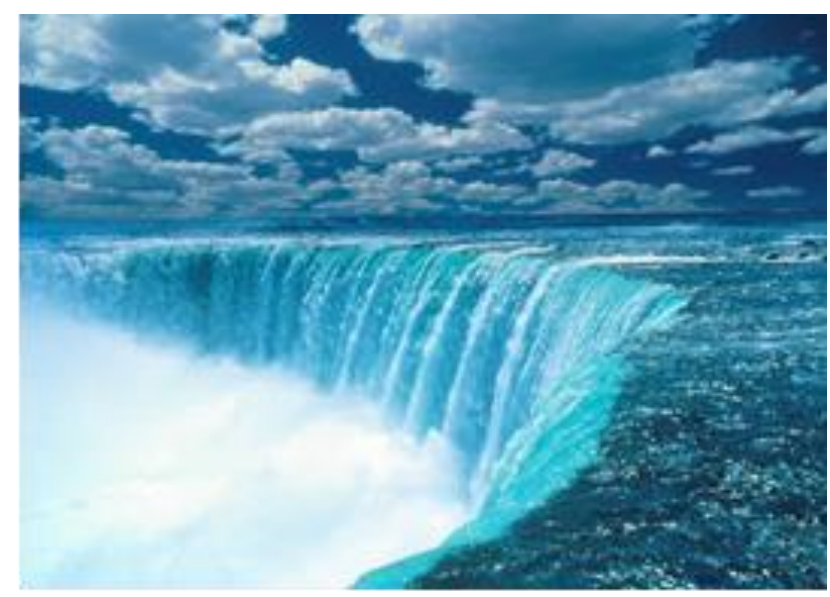

Figure 2. Routine problem of fantasy context image

Specifically, Case 1 corresponds to a student from a municipal educational institution in the Los Lagos Region; Case 2, from a municipal educational institution in the Los Ríos Region; Case 3, from a private subsidized educational institution in the Los Lagos Region; Case 4, from a private subsidized educational institution in the Los Rios Region; Case 5, a student from a private paid educational institution in the Los Lagos Region.

\section{Instruments}

In order to describe and analyse the academic performance and the errors of the students in the resolution of problems, a test of resolution of 11 problems contextualized to the quadratic function and open answer is elaborated and applied, which was previously validated by content and by means of the judgment of ten experts in resolution of problems in mathematics (Skjong \& Wentworth, 2001) considering an $85 \%$ of congruence among their answers, to accept as valid the type of problem that finally conforms the test of mathematics, which initially had 15 problems.

The result obtained in the mathematics test determines the academic performance of the students under study. For its resolution, they had 2 hours and 30 minutes and were applied in December 2019 in their respective educational establishments. The distribution of the test problems, according to the classification of types of mathematical problems proposed by Díaz and Poblete (2001) was as follows: Problem 1 (P1) routine of realistic context, P2 routine of realistic context, P3 routine of fantasist context, $\mathrm{P} 4$ non-routine, $\mathrm{P} 5$ routine of realistic context, P6 routine of fantasist context, P7 routine of realistic context, P8 routine of purely mathematical context, $\mathrm{P} 9$ routine of purely mathematical context, P10 routine of fantasist context and P11 routine of realistic context.

The academic performance of the students is determined, using the Rash Model adapted by (Díaz \& Poblete, 2001). This model includes a score scale that indicates the different progress levels of students when solving a problem correctly. This four-point scale is used to record every detail in student's processes of problem solving: No Start: The student is unable to start the problem or delivers work which is meaningless ( 0 point), Focus: The student focuses the problem with a meaningful work, indicating comprehension of the problem, yet faces difficulties easily (1 point), Substance: Sufficient details show that the student has been oriented to a rational solution, yet relevant error $\mathrm{s}$ or wrong interpretations prevent the process of the correct resolution (2 points), Result: The problem is about to be resolved, yet few mistakes lead to a wrong final solution (3 points), Completion: The proper method has been used and it has led to the correct solution (4 points).

To describe the errors shown, the classification model proposed by Socas (1997) is used, which includes errors that have their origin in an obstacle, in the absence of meaning and in emotional and affective attitudes. For the affective and emotional attitudes, immediately after the quadratic function test is completed, the case studies are consulted through a brief opinion questionnaire, the possible causes of obstacles in the resolution of a problem, whose response options were blockage, lack of motivation, lack of concentration (excessive confidence), forgetfulness, omission associated with their disposition for mathematics.

\section{RESULTS}

To show the analysis on the classification of errors and academic performance by each case study, they are presented as examples on quadratic function, problems according to their nature and context.

The $\mathrm{P} 3$, it is according to its nature routine and fantasist context, that is, it is a problem fruit of the imagination and has no basis. In this problem the quadratic function is given, and it is requested to determine the time that takes a drop to fall and its graphic representation. Figure 2 corresponds to the way in which the problem was presented to the students.

"Problem 3: When a drop of water from the top of Niagara Falls into the pit at the bottom, the height $h$, in meters, from the water in the pit can be determined by the equation $h=$ $-16 t^{2}+176$. In the equation, $t$ is the time in seconds from when the drop falls into the waterfall.

a) Determine the time it takes for the drop to reach the bottom of the waterfall in the pit (when $h=0$ ).

b) Graph the drop jump".

Both the academic performance evidenced in each of the five case studies (Figure 3) and the errors according to their origin recorded in this problem (Figure 4) are presented below.

According to the scheme in Figure 3, case 1 fails to begin the resolution of the problem. On the other hand, case 4 had the problem almost solved, but the lack of the function's graph leads to an incomplete final solution. The errors committed on time range from handing in the 


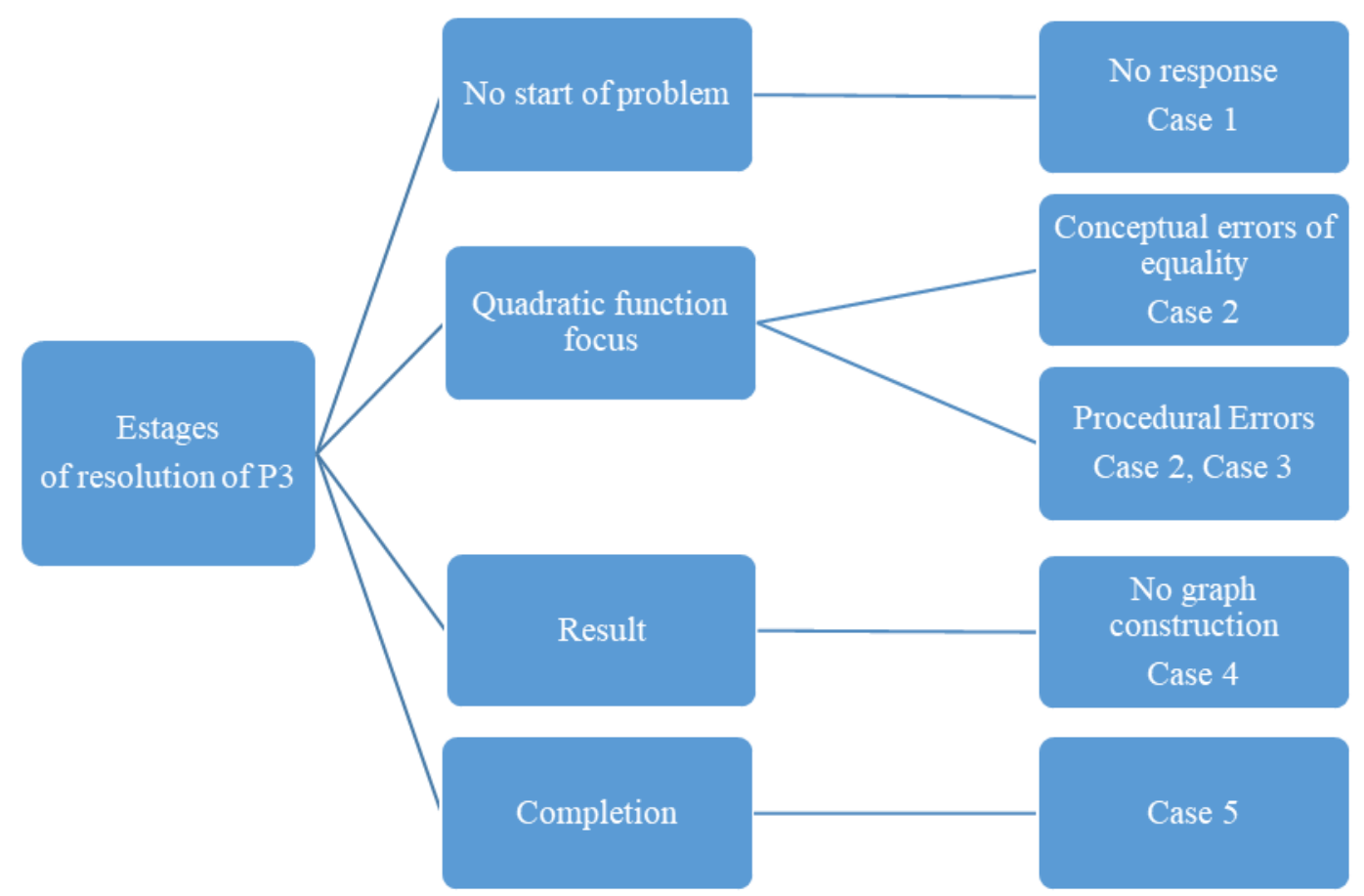

Figure 3. Errors and academic performance in routine fantasist context problem

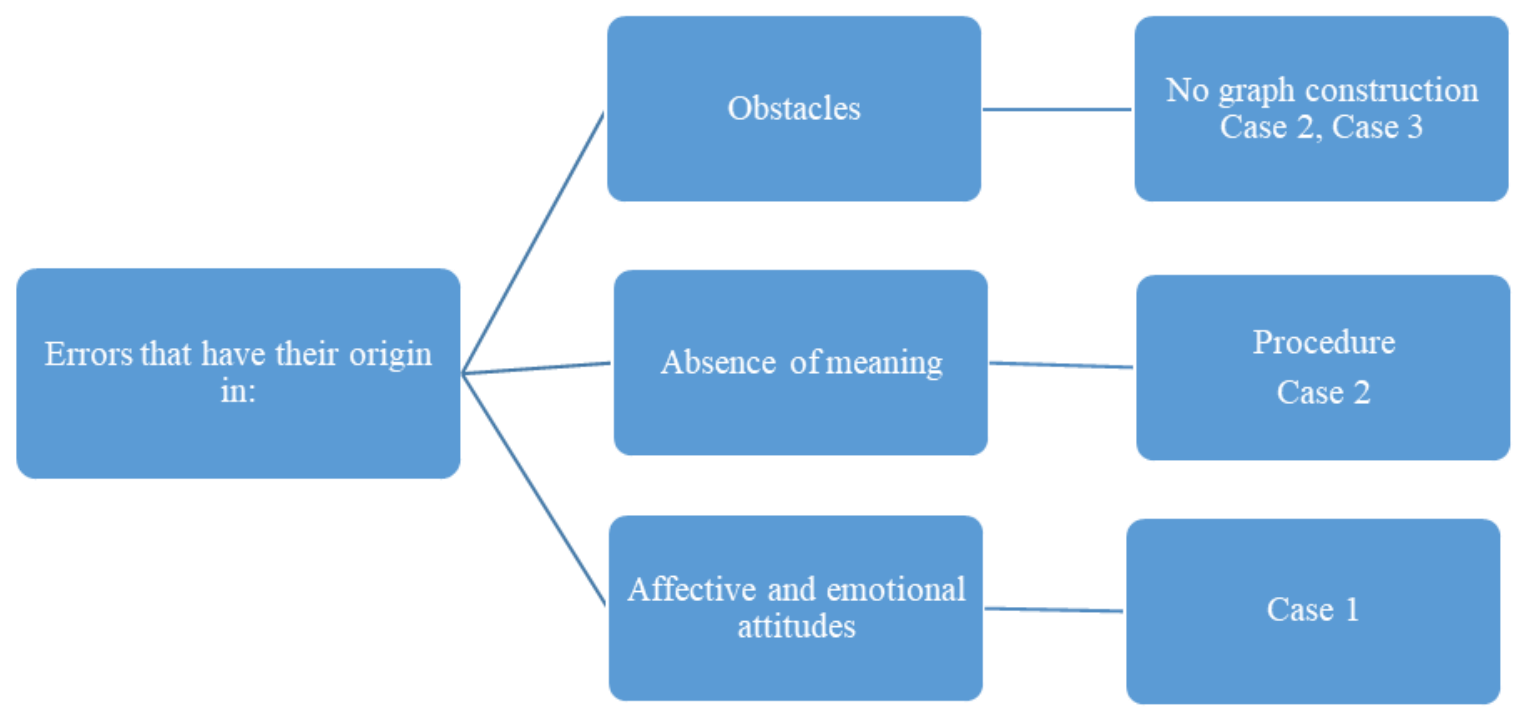

Figure 4. Errors according to their origin in routine problem of fantasist context

work without starting the resolution, errors in basic concepts such as the sense of the equal sign which are errors of a strictly algebraic nature and have no explicit relation with arithmetic, since the sense of this sign constitutes the passage from arithmetic to algebra and formal substitution. Procedural errors, because of the inappropriate use of the formula of the given quadratic function and the lack of construction of the graph of the function. Only case 5 achieves the result using an appropriate method and thus establishing the correct solution.

Figure 4 shows the errors classified according to their origin, these are recorded indistinctly in the obstacles with cases 2 and 3, noting that when the knowledge is used in another context, inadequate responses are produced. In addition, case 2 presents errors due to the absence of meaning produced because the student does not properly use the formula to find the time it takes for the drop to reach the bottom of the waterfall in the pit.

The errors that come from emotional and affective attitudes are recorded in the responses of Case 1 and 2. Case 2 achieves a certain degree of progress in solving the problem, while Case 1 does not respond to the problem. Consulted because lead them not to achieve the resolution of the routine problem and of fantasist context, they opt for the options of forgetting the concepts and blocking to initiate the resolution in an effective way. Figure 5 presents Case 2, which is present 
3) Cuando una gota de agua desde la parte superior de las cataratas del Niágara cae a la fosa en la parte inferior, la altura $h$, en metros, con respecto del agua en la fosa puede determinarse mediante la ecuación $h=-16 t^{2}+176$. En la ecuación, $t$ es el tiempo en segundos, a partir de que la gota cae en la cascada.

a) Determina el tiempo que tarda la gota en llegar a la parte inferior de la cascada en la fosa (cuando $h=0$ ).

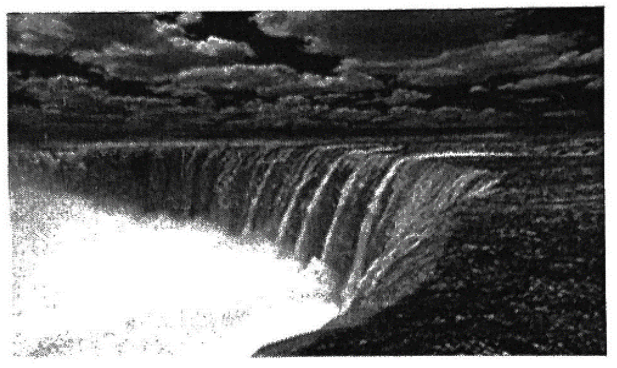

b) Grafica el salto de la gota

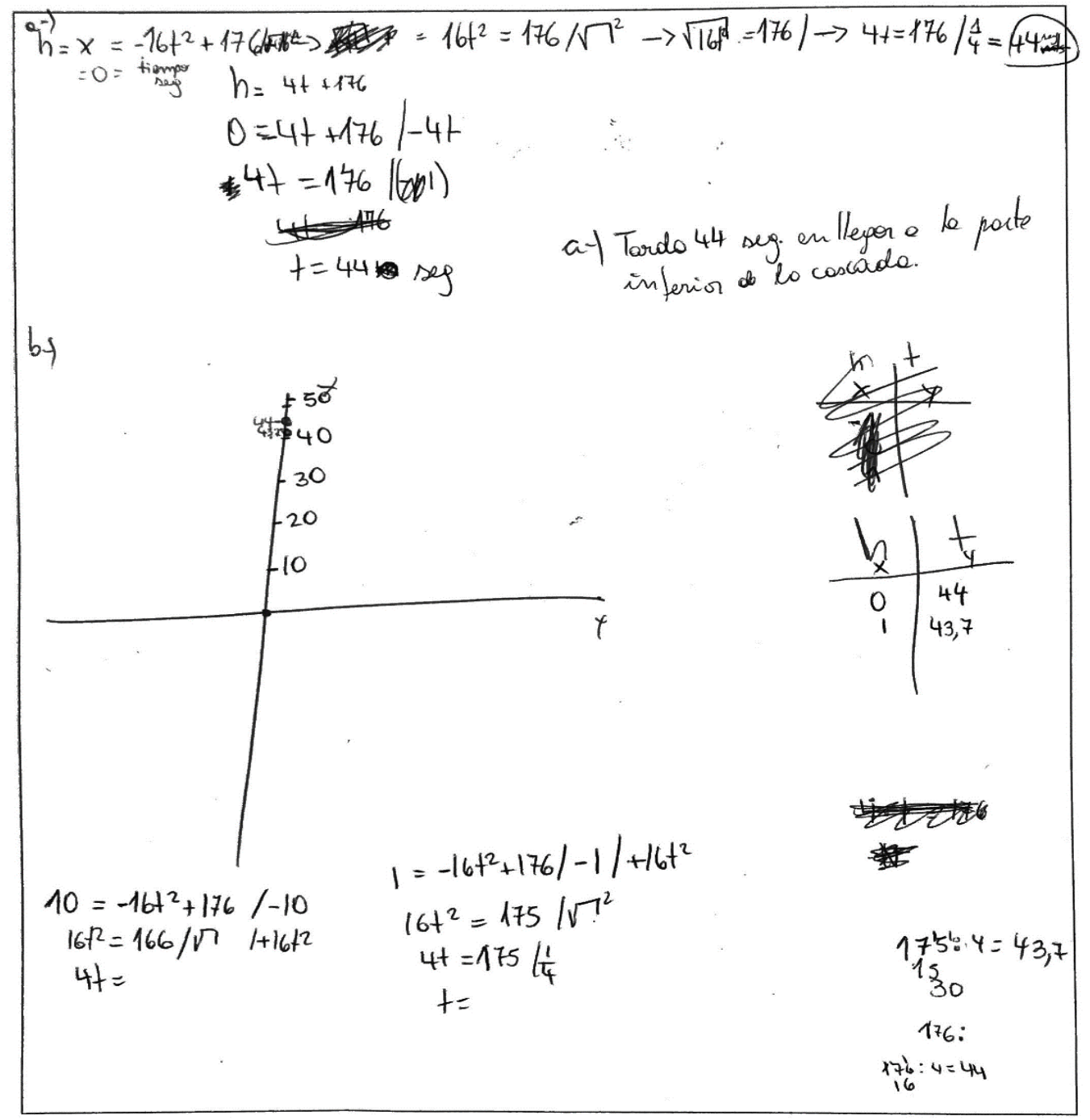

a) It delay $44 \mathrm{sec}$. to reach the bottom of the waterfall

Figure 5. Response of case 2 to the routine problem of fantasist context

in all types of errors in the development of the routine P3 fantasist context.

According to Figure 5, case 2 initiates different mathematical procedures, but when working with the function $16 \mathrm{t}^{2}=176$ and wanting to search for its roots, it presents difficulties associated with mathematical thought processes, evidencing errors associated with obstacles such as an acquired knowledge of the function's graph, not as a lack of knowledge, but being in another context, it resulted in an inadequate advance. Errors are also registered with origin in the absence of sense based on algebra, when the student in his procedure applies square root only in one member of the equality $\sqrt{16 \mathrm{t}^{2}}=176$ generating an erroneous result.

The P4 is non-routine in nature, in the sense that the student does not know an answer or a previously established procedure or routine for performing it. The 


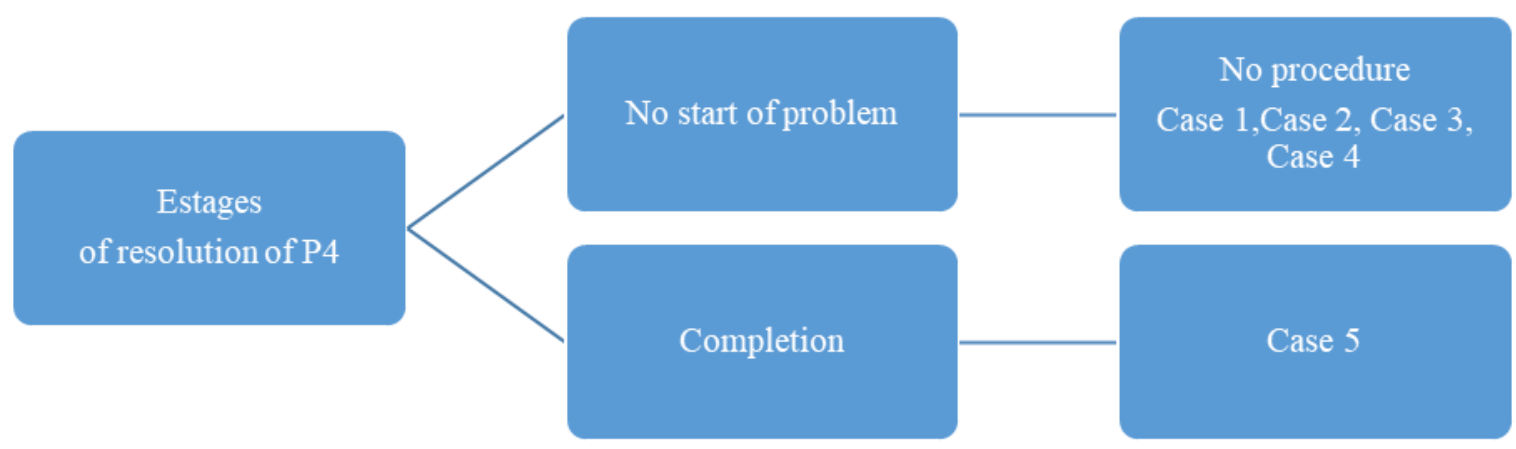

Figure 6. Academic Performance in Non-Routine Problems

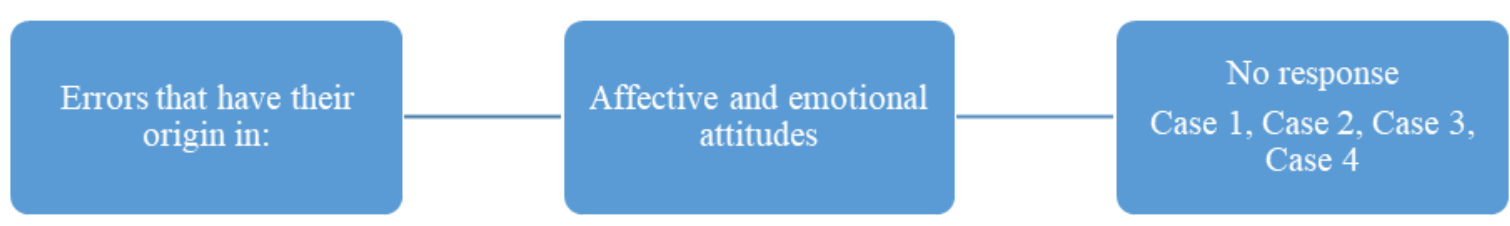

Figure 7. Errors according to their origin in non-routine problem

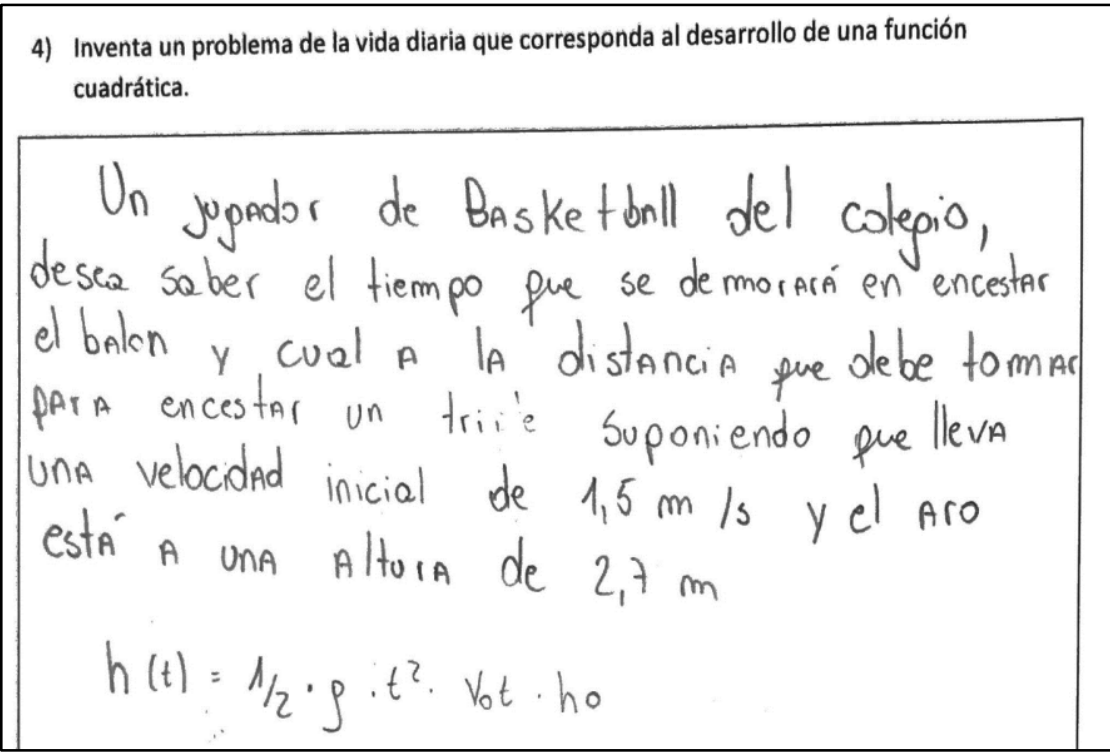

A school basketball player, you want to know how long it will take shoot the ball and what is the distance he should take to shoot a triple assuming it has an initial velocity of $1.5 \mathrm{~m} / \mathrm{s}$ and the hoop is at a height of $2,7 \mathrm{~m}$

$\mathrm{h}(\mathrm{t})=1 / 2 \cdot \mathrm{g} \cdot \mathrm{t}^{2} \cdot \mathrm{V}_{0} \mathrm{t} \cdot \mathrm{h}_{0}$

Figure 8. Case 5 response to non-routine problem

student is asked to invent a problem whose mathematical object is a quadratic function.

"Problem 4: Invent a problem of daily life that corresponds to the development of the quadratic function".

Figures 6 and 7 present the academic performance and errors according to their origin recorded in the five case studies, respectively.

According to Figure 6, four of five case studies fail to start the problem and do not record any mathematical procedure. Only case 5 succeeds in creating an everyday problem which can be solved using the quadratic function as a mathematical object.
Regarding the errors, cases 1, 2, 3 and 4 related to affective and emotional attitudes are evident, without having an answer to associate a mathematical object with the contextualization of the same. Consulted through the reasons why they did not respond to the non-routine problem, their answers are associated with forgetting the subject, blocking because of the difficulty presented by the type of problem. Figure 8 shows case 5, which was the only one that achieved a complete.

It should be noted that Case 5 uses the formula that is part of the routine P1 of realistic context, which was given an explicit context, however, it demonstrates an 


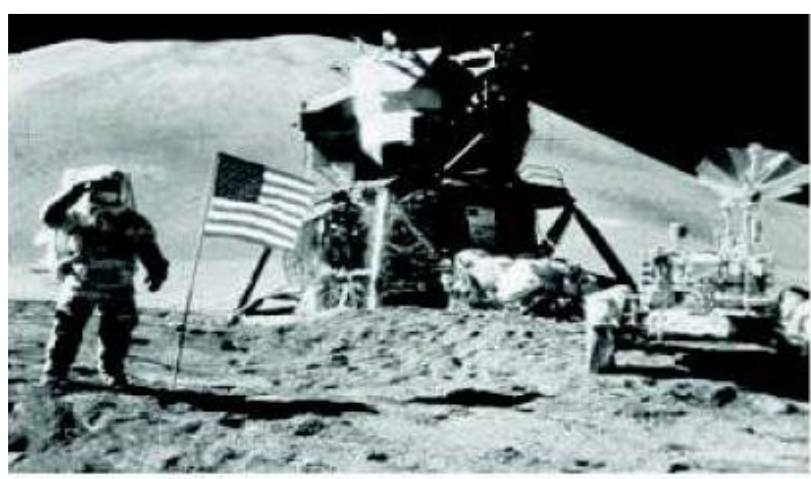

Figure 9. Realistic routine context problem image

ability to formulate a problem situation of contextualization of the quadratic function, in which it manages to involve the formula known to it.

The P5 is, according to its nature, routine, and realistic context, that is, it is susceptible to being produced because it is a simulation of reality. It asks the 5 students to substitute the data and information given in the quadratic formula and determine the time it will take Neil Armstrong to touch the ground.

"Problem 5: The gravity on the Moon is about one-sixth that of the Earth. Suppose that Neil Armstrong is on the Moon, standing on a hill 60 meters high. If he jumps up at a speed of 40 meters per second, how long will it take him to touch the ground at the bottom of the hill?"

Figure 10 shows the academic performance shown in each of the five case studies and the errors according to their origin recorded in this problem (Figure 11).
Based on the scheme that gives an account of the academic performance, it is visualized that the problem was of high difficulty for the five students, given that cases 1, 2, 4 and 5 do not manage to start the resolution of the problem and in addition they do not present procedure, that is to say, they are incapable of starting the problem or they delivered it without resolution demonstrating that for them it has no meaning. Only case 3 manages to reach the focus stage, indicating an understanding of the application of the quadratic function, but it quickly encounters a difficulty and in its discreet progress, presents obstacles in arithmetic.

With regard to errors classified according to their origin, these are mostly recorded in affective and emotional attitudes and correspond to cases 1, 2, 3 and 4 . Only case 3 presents errors with origin in the absence of meaning, as a result of not having assimilated relationships and processes in an arithmetical context, which is manifested in the multiplication of fractions. The answers about the reasons for the lack of resolution are related to blocks produced by the work of solving problems in mathematics and forgetting how to pose a quadratic function when the formula is not previously known. Figure 12 presents case 3 in the development of the routine P5 of realistic context.

Case 3 shows that the algebraic procedure of the quadratic function is known, however, in the numerical coefficient that is part of the quadratic variable it does not consider the value: $g=-32 \mathrm{~m} / \mathrm{s}^{2}$ which conditions its result. This error is mainly due to the absence of meaning originating in arithmetic, because of not having

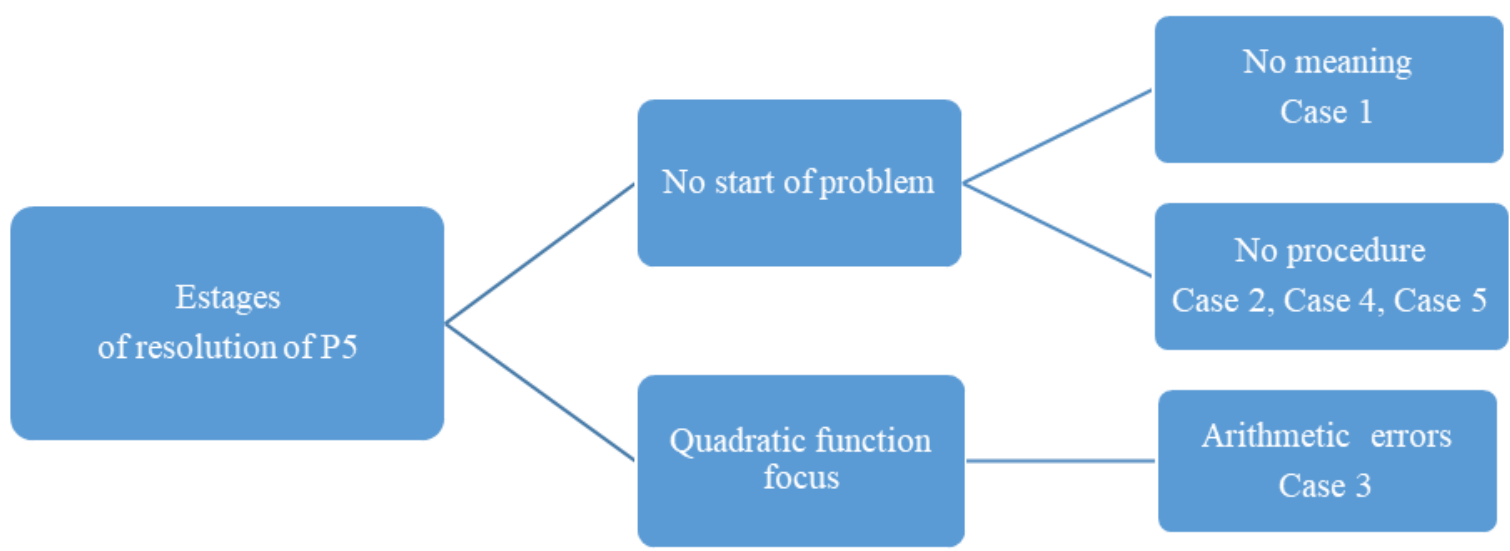

Figure 10. Academic performance in a realistic routine problem

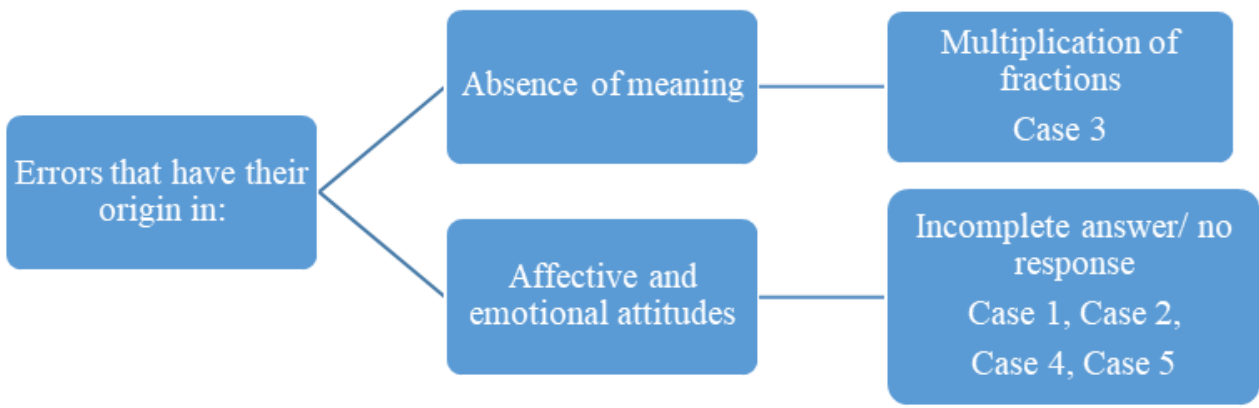

Figure 11. Errors according to their origin in realistic context routine problem 
5) La gravedad en la Luna equivale más o menos a un sexto de la terrestre. Supongamos que Neil Armstrong se encuentra en la Luna, parado sobre una colina de 60 metros de altura. $\mathrm{Si}$ salta hacia arriba con una velocidad de 40 metros por segundo, ¿cuánto tardará en tocar el suelo que está al pie de la colina?

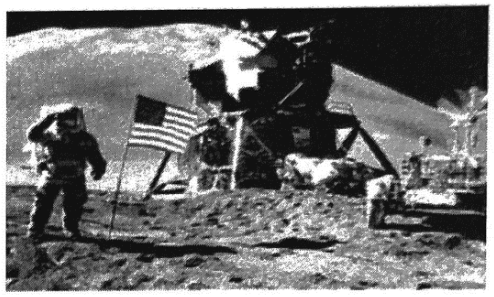

$$
\begin{array}{ll}
6 t=x & 0=0,5 \cdot \frac{100}{6} x^{2}+40 x+60 \\
6 L=\frac{x}{6} & 0=5 x^{2}+40 x+60
\end{array}
$$

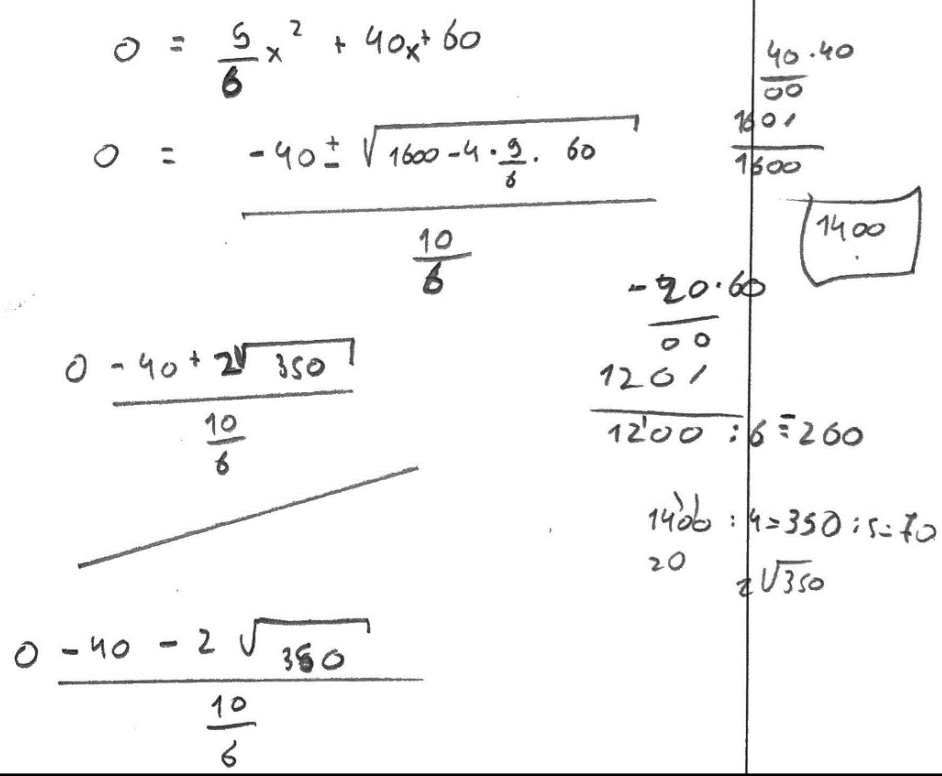

Figure 12. Response of case 3 to the routine problem of realistic context

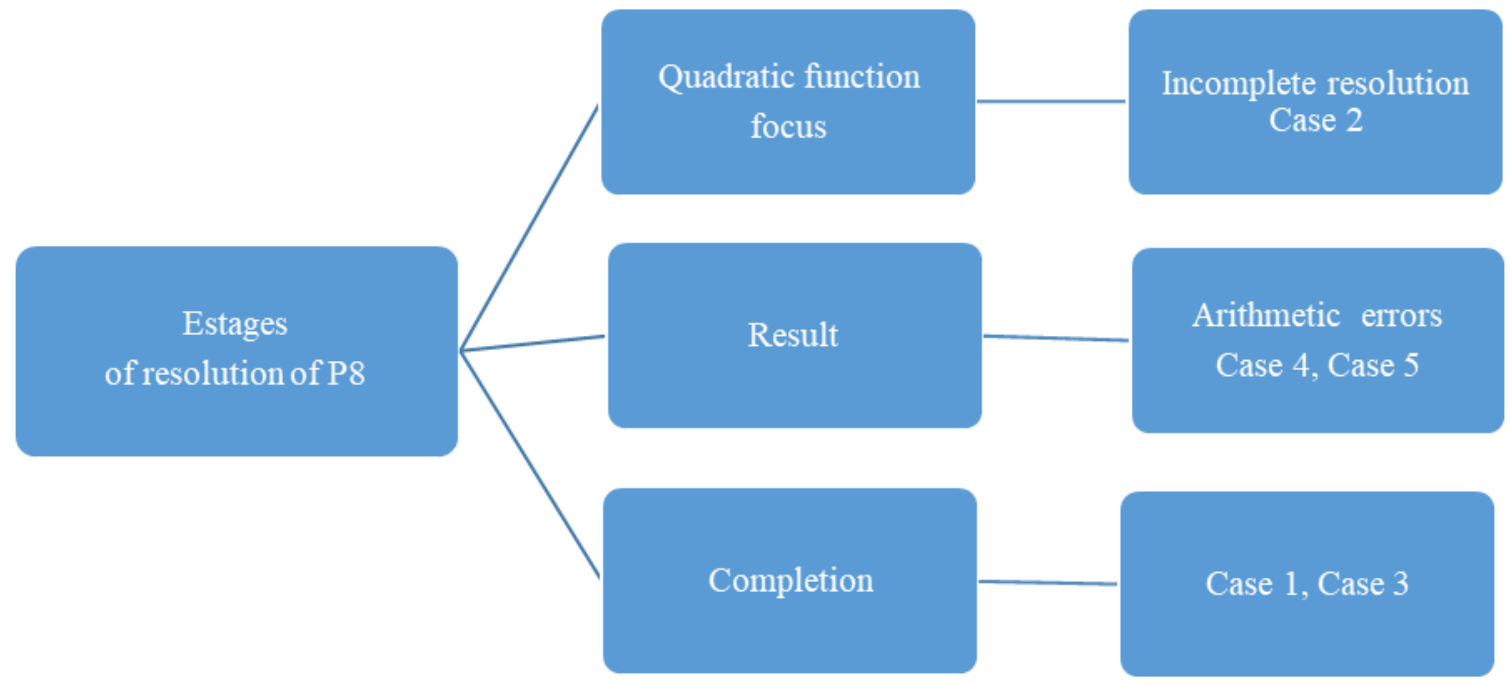

Figure 13. Academic performance on routine problem of purely mathematical context

assimilated relationships and processes in an arithmetical context.

The P8 is, according to its routine nature of purely mathematical context, that is, it refers exclusively to mathematical objects, numbers, relations and arithmetic operations, geometrical figures, etc. In this problem a rectangle has been given and it is requested to calculate its diagonal as a function of the given area.

"Problem 8: Calculate the diagonal of a rectangle knowing that the base is equal to three quarters of the height and that the area is $48^{\prime \prime}$. Figures 13 and 14 show the steps in solving the problem and the errors according to their origin, respectively. 


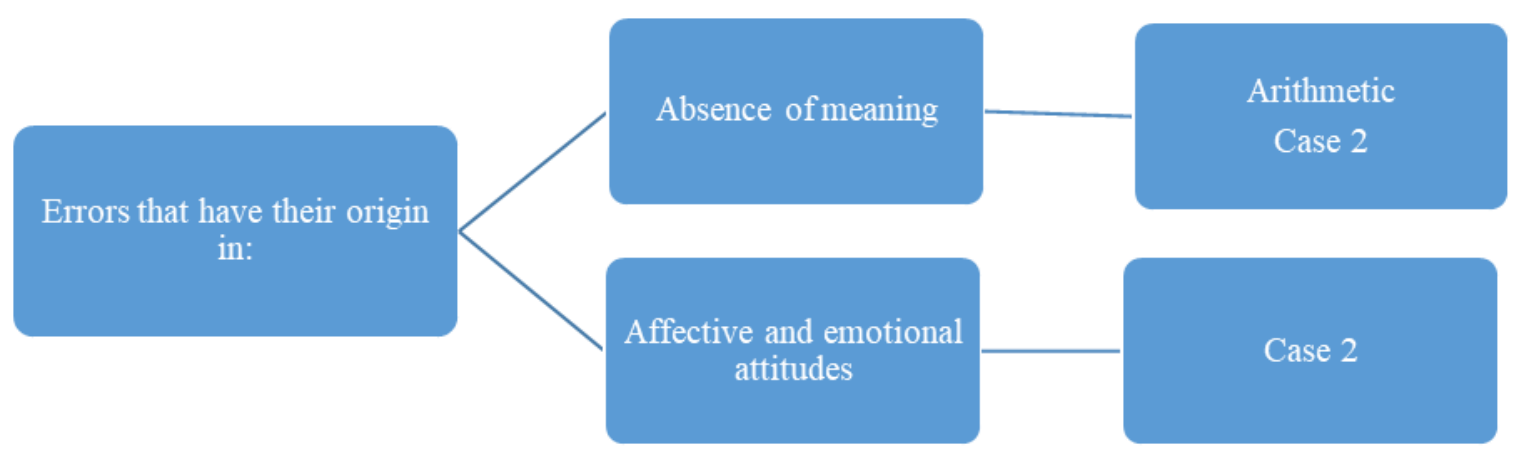

Figure 14. Errors according to their origin in a purely mathematical routine problem

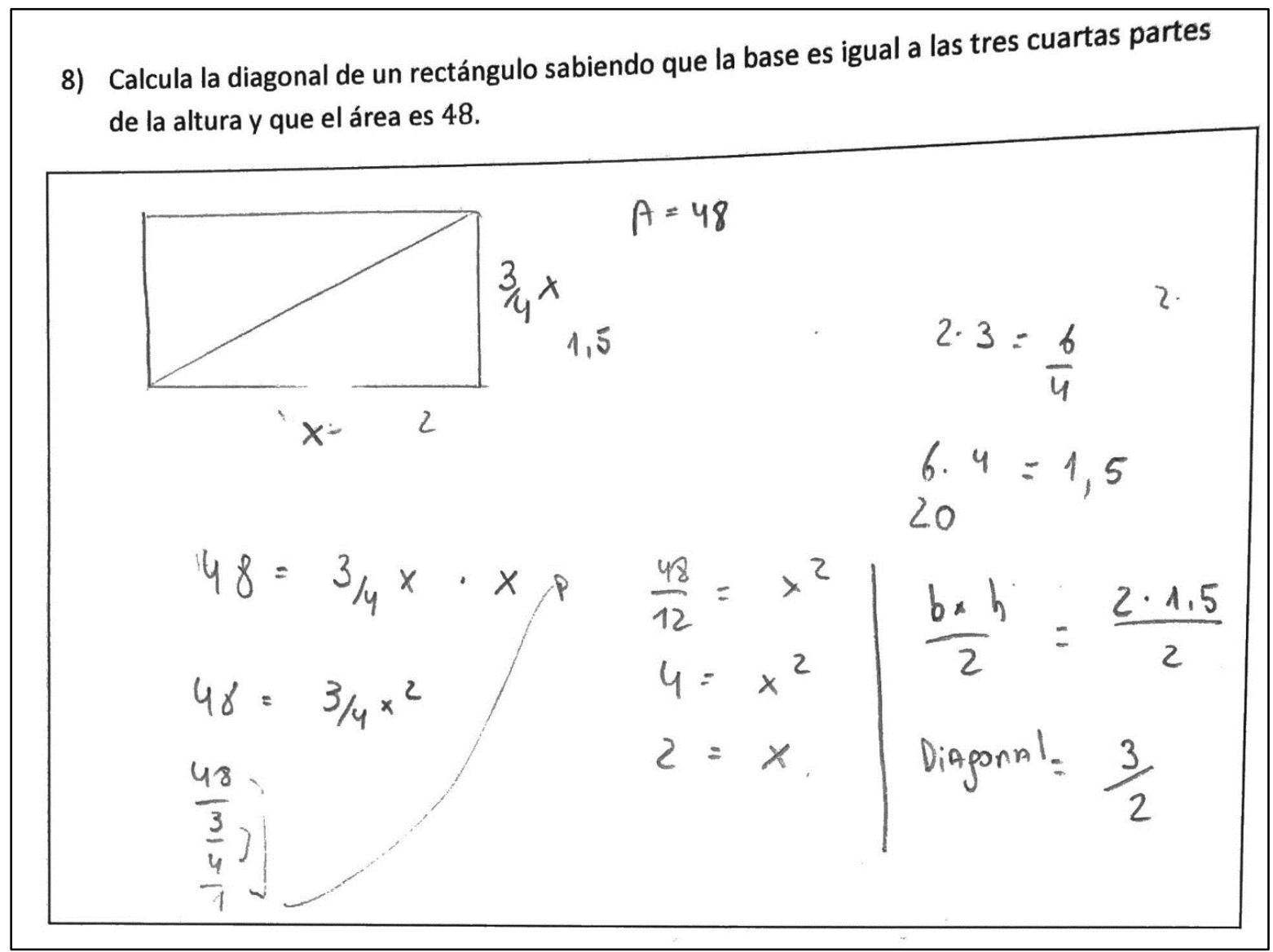

Figure 15. Response of case 4 to the purely mathematical routine context problem

Based on the scheme in Figure 13, overall academic performance is high on this issue. In a student analysis, cases 1 and 3 achieve complete resolution of the routine problem in a purely mathematical context. Cases 4 and 5 although they had difficulties in the procedure of resolution in the quadratic equation, indicate understanding of how to solve a problem that refers to relations and algebraic operations, which have been previously known by the students, but they found difficulties in the operability of the equation and its calculation, leading to erroneous results. Only case 2 remains in the focus stage of the quadratic function, finding a difficulty that did not allow it to advance to the next stage of resolution. With respect to the origin of the errors, these are outlined in Figure 14.
Analyzing the errors according to their origin, it was found that these are only recorded in case 2 and correspond to errors due to the absence of meaning associated with arithmetic procedures. With respect to errors due to emotional and affective attitudes, when consulted, the student opts for the blocking response and forgets how to pose a quadratic function. Next, in Figure 15 , case 4 is presented in the development of the routine P8 of purely mathematical context.

Case $4 \mathrm{y}$, except for the spatial location of the sides of the rectangle, manages to pose the quadratic equation properly, but when working with the equation $3 / 4 x^{2}=$ 48 , it does not manage to clear the variable $x$, because it does not apply the multiplicative inverse correctly and this makes the final result incorrect. 


\section{CONCLUSION AND DISCUSSION}

This study purpose was to gain a better understanding of the errors made by students, belonging to the three types of educational establishments that exist in school education in Chile in solving types of quadratic function application problems.

The results first of all revealed that in relation to the academic performance of the five case studies and according to the problems that in their resolution only reached the result stage - previous to the final phase of correct resolution - it was because minor difficulties led to a wrong solution. Therefore, they can be considered of lesser importance since they can be overcome through conscious work by the student. Although they were presented in two of the five cases, they are not as relevant to the objectives of this paper, because the stages prior to resolution are considered more important, as substance, focus and fundamentally, not start. In the non-beginning stage, the highest frequencies were recorded, which implies that the student was unable to start the problem or deliver a work that has no meaning. Four case studies, were left without more than one problem being solved. Only one of them managed to address all the situations of contextualization of the quadratic function, and in most of them, to adequately solve the problem posed.

Secondly, in relation to the type of problem associated with academic performance, we can indicate that those with the highest performance were the purely mathematical context routines followed with less frequency by the fantasist context routines. Purely mathematical context problems, because they refer exclusively to mathematical objects, numbers, relations and arithmetic operations, geometric figures, etc. and correspond to problems that are commonly present in literature and inherent to the usual form of practice, therefore it is foreseeable that students have had the opportunity to practice them previously. They have a fantasist context, with no basis and are the fruit of the imagination. However, they are problems that, containing clearly defined mathematical objects, are motivating for students, as they consider fantasist situations like a drop of water from Niagara Falls. This result is similar to that of Díaz (2020) in the investigation of types of problems in derivative applications with engineering students. These different and original problems manage to awaken the curiosity and motivation of the student by trying to bring fantasist elements closer to reality and the students' interests in their knowledge, so that they learn to solve these problems that have been contextualized to a specific mathematical object.

On the other hand, the problem with the greatest obstacle was the non-routine one. In this problem, the student does not know an answer or a previously established procedure or routine to carry it out. Thus, four out of five case studies did not manage to start their resolution. This result coincides with various investigations, such as that of Kaya and Kablan (2018) those who mention the difficulty of students in finding more than one solution to a non-routine problem; with Akyüz (2020) in a recent investigation with future teachers, whose performance decreased when the level of difficulty of the problem considered to be non-routine increased. In similar studies, teacher candidates showed low success in problems related to non-routine problems (Akgün, Işık, Tatar, İşleyen, \& Soylu, 2012; Dündar, 2015) with other research reporting that students tend to use arithmetic operation to solve non-routine problems.

Thirdly, the analysis of the test and answers to the opinion questionnaire, provides an idea of the most common procedural and conceptual errors in the students. It is discovered that in the cognitive errors presented in most of the cases under study, they have their origin in the absence of meaning, where procedural difficulty has predominated. In these errors, although the student demonstrates knowledge of some concepts to achieve the resolution of the problem, he or she does not achieve the link between them, generating a mixture of concepts without meaning. In general, they were limited to achieving effective resolution, which was limited by the need to apply a more basic algebraic procedure (application of additive and multiplicative inverses, resolution of the equation, etc.). In order to overcome these errors, a greater intervention of the teacher is required, but also a joint work with the student, since in this type of errors the lack of both theoretical and conceptual content is manifested, coinciding with the investigations of Agustyaningrum, Abadi and Mahmud (2018).

Errors originating in emotional and affective attitudes were the most frequent in the five case studies from both regions. When asked about the reasons for the lack of resolution in certain problems, the five case studies mostly agreed on having blockages when starting the resolution, forgetting to pose the quadratic function. These findings coincide with Lester and Kehle (2003) that recognize that the difficulty, in addition to the characteristics of a problem, also depends on the disposition, beliefs and attitudes of the students.

Similarly, research from Hall and Goetz (2013), Pekrun and Linnenbrink-Garcia (2014) has shown that students' emotions are linked to their academic performance. Generally, positive emotions, such as enjoyment of learning, show positive links to achievement, and negative emotions, such as assessment anxiety, show negative links. This fact, can provide further analysis on the reason for greater emphasis at the need to take into account the affective domain when teaching mathematics to students at any educational level and to really develop the ability to solve types of problems that contextualize a mathematical object, all levels of the education system. 


\section{REFERENCES}

Adams, D. M., McLaren, B. M., Durkin, K., Mayer, R. E., Rittle-Johnson, B., Isotani, S., \& Van Velsen, M. (2014). Using erroneous examples to improve mathematics learning with a web-based tutoring system. Computer in Human Behavior, 36, 401-411. https:/ / doi.org/10.1016/j.chb.2014.03.05307475632/Ó2014

Agustyaningrum, N., Abadi, A., \& Mahmudi, A. (2018). An analysis of students' error in solving abstract algebra tasks. Journal of Physics: Conference Series. 1097. 012118. https://doi.org/10.1088/17426596/1097/1/012118

Akgün, L., Işık, C., Tatar, E., İşleyen, T., \& Soylu, Y. (2012). Transfer of mathematical knowledge: series. Australian Journal of Teacher Education, 37(3), 83-89. https://doi.org/10.14221/ajte.2012v37n3.2

Akyüz, G. (2020). Non-routine problem solving performances of mathematics teacher candidates. Educational Research Review, 15(5), 214-224. https: / / doi.org/10.5897/ERR2020.3907

Bajaña, C. (2019). Didactic proposal for teaching quadratic equations and functions, through the use of "Desmos Graphing Calculator" [Propuesta didáctica para la enseñanza de funciones y ecuaciones cuadráticas, a través del uso de: "Desmos Graphing Calculator"]. (Bachelor), Universidad de Cuenca, Ecuador.

Beilock, S. L., Schaeffer, M. W., \& Rozek, C. S. (2017). Understanding and addressing performance anxiety. In A. J. Elliot, C. S. Dweck, \& D. S. Yeager (Eds.), Handbook of competence and motivation: Theory and application (p. 155-172). New York, NY: The Guilford Press.

Benning, I., \& Agyei, D. D. (2016). Effect of using spread sheet in teaching quadratic functions on the performance of senior high school students. International Journal of Education, Learning and Development, 4(1), 11-29.

Berger, N., Mackenzie, E., \& Holmes, K. (2020). Positive attitudes towards mathematics and science are mutually beneficial for student achievement: a latent profile analysis of TIMSS 2015. The Australian Educational Researcher, 47, 409-444. https:/ / doi.org/10.1007/s13384-020-00379-8

Blanco, L., Guerrero, E., \& Caballero, A. (2013). Cognition and affect in mathematics problem solving with prospective teachers. The Mathematics Enthusiast, 10(1-2), 335-364.

Boesen, J., Lithner, J., \& Palm, T. (2010). The relation between types of assessment tasks and the mathematical reasoning students use. Educational Studies in Mathematics, 75(1), 89-105. https: / / doi.org/10.1007/s10649-010-9242-9
Budd, C., \& Sangwin, C. (2004). 101 uses of a quadratic equation: Part II. Magazine Living Mathematics, 30 [on-line]. Retrieved on 3 April 2020 from http:/ / plus.maths.org/content/os/issue30/featur es/quadratics/index

Çelik, Ö., \& Güzel, B. (2019). An instructional sequence triggering students' quantitative reasoning during learning of quadratic functions. Turkish Journal of Computer and Mathematics Education, 10(1), 157-194. https:/ / doi.org/10.16949/turkbilmat.446403

Chapman, O. (2013). Mathematical-task knowledge for teaching. Journal of Mathematics Teacher Education, 16, 1-6. https:/ / doi.org/10.1007/s10857-013-9234-7

Davis, J. D., Smith, D. O., Roy, A. R., \& Bilgic, Y. K. (2014). Reasoning-and-proving in algebra: The case of two reform-oriented U.S. Textbooks. International Journal of Educational Research, 64, 92106. https:/ / doi.org/10.1016/j.ijer.2013.06.012

Díaz V. (2020). Difficulties and performance in mathematics competences: solving problems with derivatives. International Journal of Engineering Pedagogy, 10(4), 35-53. https://doi.org/10.3991/ ijep.v10i4.12473

Díaz, V. (2019). Limits Problem Solving in Engineering Careers: Competences and Errors. International Journal of Business, Human and Social Sciences, 13(7), 951-957. https:/ / doi.org/10.5281/zenodo.3299965

Díaz, V., \& Poblete, A. (2001). Categorizing types of problems in algebra [Categorizando tipos de problemas en álgebra]. UNO. Revista de Didáctica de las Matemáticas, 27, 93-103.

Díaz, V., \& Poblete, A. (2018). Use of didactic models of the teachers of mathematics in the teaching of logarithmic, quadratic and exponential functions [Uso de modelos didácticos de los docentes de matemáticas en la enseñanza de funciones logarítmicas, cuadráticas y exponenciales]. Paradigma, 39(1), 353-372.

Díaz, V., Belmar, H., \& Poblete, A. (2018). Emotional manifestation and modeling of a mathematical function [Manifestación emocional y modelamiento de una función matemática]. Bolema Boletim de Educação Matemática, 32(62), 1198-1218. https:/ / doi.org/10.1590/1980-4415v32n62a22

Didis, M. G., Bas, S., \& Erbas, A. (2011). Students' reasoning in quadratic equations with one unknown. Proceedings of the Seventh Congress of the European Society for Research in Mathematics Education. University of Rzeszów, Poland. Retrieved on 18 April 2020 from http:/ / www.ezproxy.uvm.edu/cerme7.univ.Rzes zow pl/WG/3/CERME7_WG3_Gozde.pdf

Dündar, S. (2015). The investigation of teacher candidates' skills of solving exercises and non- 
routine problems related to the topic of series. Kastamonu Education Journal, 23(3),1293-1310.

Durkin, K., \& Rittle-Johnson, B. (2012). The efectiveness of using incorrect examples to support learning about decimal magnitude. Learning and Instruction, 22(3), 206-214. https://doi.org/10.1016/j.learnin struc.2011.11.001

Ellis, A. B., \& Grinstead, P. (2008). Hidden lessons: How a focus on slope-like properties of quadratic functions encouraged unexpected generalizations. The Journal of Mathematical Behavior, 27(4), 277-296. https:/ / doi.org/10.1016/j.jmathb.2008.11.002

Eraslan, A. (2008). The notion of reducing abstraction in quadratic functions. International Journal of Mathematical Education in Science and Technology, 39(8), 1051-1060. https://doi.org/10.1080/ 00207390802136594

Esquer, M. P., Robles, A., Cosmes, S., \& Ansaldo, J. (2017). Didactic proposal with quadratic functions of problems in context at a higher level [Propuesta didáctica con funciones cuadráticas de problemas en contexto a nivel superior]. In F.Rodríguez \& R. Rodríguez (Eds.), Memoria de la XVII Escuela de Invierno en Matemática Educativa (pp. 376-381). Oaxaca: Red Cimates.

Farez, M. (2018). Solving quadratic functions through the use of learning objects by second year high school students, in the feedback phase [Resolución de funciones cuadráticas mediante el uso de objetos de aprendizaje por parte de estudiantes de segundo año de bachillerato, en la fase de retroalimentación]. (Master Thesis), Universidad de Cuenca, Ecuador.

Fuadi, I., Minarni, A., \& Banjarnahor, H. (2017). Analysis of students' mathematical problem solving ability in ix grade at junior high school ar-rahman percut. International Journal of Novel Research in Education and Learning, 4(2), 153-159.

Fulgar, A. (2020). Comparative analysis of mathematics proficiency and attitudes toward mathematics of senior high school student 2020. International Journal of Scientific and Research Publications, 10(5), 211-222. https://doi.org/10.29322/IJSRP.10.05. 2020.p10125

Gómez-Blancarte, A., Guirette, R., \& Morales-Colorado, F. (2017). Proposal for treating global interpretation of the quadratic function using the software GeoGebra [Propuesta para el tratamiento de interpretación global de la función cuadrática mediante el uso del software GeoGebra]. Educación Matemática, 29(3), 189-224. https://doi.org/ 10.24844/em2903.07

Good. T. L., \& Lavigne, A.L. (2018). Looking in classrooms (11th ed.). New York, NY: Routledge. https://doi.org/10.4324/9781315627519
Große, C. S., \& Renkl, A. (2007). Finding and fixing errors in worked examples: can this foster learning outcomes? Learning and Instruction, 17(6), 612-634. https:/ / doi.org/10.1016/j.learninstruc.2007.09.008

Haciomeroglu, G. (2013). The field experiences of student teachers and effective mathematics teaching in Turkey. Australian Journal of Teacher Education, 38(2), 131-142. https:// doi.org/10.14221 /ajte.2013v38n2.5

Hall, N., \& Goetz, T. (2013). Emotion, motivation, and selfregulation: A handbook for teachers. UK: Esmerald Group Publishing Limited.

Heinze, A., \& Reiss, K. (2007). Mistake-handling activities in the mathematics classroom: Effects of an in-service teacher training on students' performance in geometry. In J.Woo, H. C. Lew, K. S. Park, \& D. Y. Seo (Eds.). Proceedings of the 31st Conference of the International Group for the Psychology of Mathematics Education. Seoul: PME.

Henderson, S. (2012). Why the journey to mathematical excellence may be long in Scotland's primary schools. Scottich Education Review, 44(1), 46-56.

Hernández, J., Castañeda, A., \& González, R. (2019). The solution of an unconventional mathematical problem by university students [La solución de un problema matemático no convencional por estudiantes universitarios]. Revista Científica, 35(2). https:// doi.org/10.14483/23448350.14863

Hernández, R., Fernández, C., \& Baptista, P. (2014). Investigation methodology [Metodología de la Investigación]. México: McGraw-Hill.

Jäder, J., Lithner, J., \& Sidenvall, J. (2019). Mathematical problem solving in textbooks from twelve countries. International Journal of Mathematical Education in Science and Technology. https:// doi.org/10.1080/0020739X.2019.1656826

Kaya, S., \& Kablan, Z. (2018). The Analysis of the Studies on Non-Routine Problems. Necatibey Faculty of Education. Electronic Journal of Science and Mathematics Education, 12(1), 44-25. https:// doi.org/10.17522/balikesirnef.437652

Kilic, H. (2011). Preservice secondary mathematics teachers' knowledge of students. Turkish Online Journal of Qualitative Inquiry, 2(2), 17-35.

Kotsopoulos, D. (2007). Unravelling student challenges with quadratics. Australian Mathematics Teacher, 63(2), 19-24.

Langat, A. C. (2015). Students' attitudes and their effects on learning and achievement in Mathematics: A Case study of public secondary schools in Kiambu County, Kenya. (Master Thesis), Kenyatta University, Kenya.

Loibl, K., \& Rummel, N. (2014). Knowing what you don't know makes failure productive. Learning and Instruction, 34, 74-85. https://doi.org/10.1016/ j.learninstruc.2014.08.004 
Martinez-Planell, R., Torres, J., \& Hernandez, I. (2015). Students' understanding of quadratic equations. International Journal of Mathematical Education in Science and Technology, https://doi.org/10.1080/ 0020739X.2015.1119895

McLaren, B. M., Adams, D. M., \& Mayer, R. E. (2015). Delayed learning effects with erroneous examples: a study of learning decimals with a web-based tutor. International Journal Artificial Intelligence in Education, 25, 520-542. https://doi.org/10.1007/ s40593-015-0064-x

McLaren, B. M., Adams, D., Durkin, K., Goguadze, G., Mayer, R. E., Rittle-Johnson, B., \& Van Velsen, M. (2012). To err is human, to explain and correct is divine: a study of interactive erroneous examples with middle school math students. Proceedings in the 21st Century learning for 21st Century skills (pp. 222-235). Berlin: Springer. https://doi.org/ 10.1007/978-3-642-33263-0_18

Mensah, J. K., Okyere, M., \& Kuranchie, A. (2013). Student attitude towards mathematics and performance: Does the teacher attitude matter. Journal of Education and Practice, 4(3), 132-139.

Metcalf, R. C. (2007). The nature of students' understanding of quadratic functions. (Doctoral Thesis), University of New York at Buffalo, USA.

Ministerio de Educación de Chile MINEDUC (2019). Fundamentals curricular bases $3 \mathrm{rd}$ and 4 th middle [Fundamentos bases curriculares $3^{\circ}$ y $4^{\circ}$ medio]. Santiago: Ministerio de Educación.

Mutambara, L.H.N., Tendere, J., \& Chagwiza, C.J. (2020). Exploring the conceptual understanding of the quadratic function concept in teachers' colleges in Zimbabwe. EURASIA Journal of Mathematics, Science and Technology Education, 16(2), em1817. https:/ / doi.org/10.29333/ejmste/112617

National Council of Teachers of Mathematics (NCTM). (2014). Principles to actions: ensuring mathematical success for all. Reston, VA: NCTM.

National Council of Teachers of Mathematics (NCTM). (2018). Catalyzing Change in High School Mathematics: Initiating Critical Conversations. Reston, VA: NCTM.

National Council of Teachers of Mathematics (NCTM). (2020). Standards for the Preparation of Secondary Mathematics Teachers. Reston, VA: NCTM.

Nielsen, L. E. J. (2015). Understanding quadratic functions and solving quadratic equations: An analysis of student thinking and reasoning. EURASIA Journal of Mathematics, Science and Technology Education, 3(4), 351-361.

OECD. (2019). OECD skills strategy 2019. Skills to shape a better future. Paris, France: OECD Publishing.

Oser, F., \& Spychiger, M. (2005). Learning is painful - on the theory of negative knowledge and a practice and error culture [Lernen ist schmerzhaft. zur theorie des negativen wissens und zur praxis der fehlerkultur]. Weinheim (Germany): Beltz.

Özaltun, C. \& Bukova, G. (2019). An instructional sequence triggering students' quantitative reasoning during learning of quadratic functions. Turkish Journal of Computer \& Mathematics Education, 10(1), 157-194. https://doi.org/10.16949/ turkbilmat.446403

Parent, J. S. S. (2015). Students' understanding of quadratic functions: Learning from students' voices. (Doctoral Thesis), University of Vermont, USA.

Pekrun, R., \& Linnenbrink-Garcia, L. (2014). Educational psychology handbook series. International handbook of emotions in education. Washington: Routledge/Taylor \& Francis Group.

Peralta-García, J., Encinas-Pablos, F., \& Cuevas-Salazar, O. (2019). Diagnosis of previous knowledge about the parábola in university students [Diagnóstico de conocimientos previos sobre la parábola en estudiantes universitarios]. Revista de Educación Superior, 3(8), 1-11. https://doi.org/10.35429/ JHS.2019.8.3.1.11

Peranginangin, S. (2017). An analysis of students' mathematics problem solving ability in vii grade at smp negeri 4 pancurbatu. International Journal of Sciences: Basic and Applied Research, 33(2), 57-67.

Peteros, E., Columna, D., Etcuban, J. O., Almerino J. P., \& Almerino, J. G. (2019). Attitude and Academic Achievement of High School Students in Mathematics Under the Conditional Cash Transfer Program. International Electronic Journal of Mathematics Education, 14(3), 583-597. https:/ / doi.org/10.29333/iejme/5770

Radatz, H. (1980). Students'errors in the mathematical learning process. For the Learning of Mathematics, 1(1), 16-20.

Rico, L. (1995). Errors in learning mathematics [Errores en el aprendizaje de las Matemáticas]. In J. Kilpatrick, P. Gómez \& L. Rico (Eds.), Educación Matemática (pp.69-108). México: Grupo Editorial Iberoamérica.

Ruli, R. M., Priatna, N., Sufyani, P., \& Endang, M. (2018). Analysis learning obstacle on quadratic function topic. International Journal of Information and Education Technology, 8(9), 681-684. https:/ / doi.org/10.18178/ijiet.2018.8.9.1122

Rushton, S.J. (2018). Teaching and learning mathematics through error analysis. Fields Mathematics Education Journal, 3(4). https://doi.org/10.1186/s40928-0180009-y

Schoenfeld, A. H. (2012). Problematizing the didactic triangle. ZDM, 44(5), 587-599. https://doi.org/ $10.1007 /$ s11858-012-0395-0 
Sisman, G. T., \& Aksu, M. (2015). A study on sixth grade students' misconceptions and errors in spatial measurement: length, area, and volume. International Journal of Science and Mathematics Education, 14(7), 1293-1319. https://doi.org/ $10.1007 /$ s10763-015-9642-5

Skjong, R., \& Wentworth, B. (2001). Expert judgement and risk perception. Proceedings of Eleventh the International Offshore and Polar Engineering Conference. Stavanger: Norway.

Socas, M. (1997). Difficulties, obstacles and errors in the learning of Mathematics in Secondary Education [Dificultades, obstáculos y errores en el aprendizaje de las Matemáticas en la Educación Secundaria]. In
L. Rico et al., (Eds.), La Educación Matemática en la enseñanza secundaria (pp. 125-154). Barcelona: Horsori.

Strickland, T. K. (2011). The effects of blended instruction and visual representations on area problems involving quadratic expressions for secondary students with mathematics learning difficulties. (Doctoral Thesis), University of Maryland, College Park, USA.

Tsovaltzi, D., Melis, E., McLaren, B. M., Meyer, A. K., Dietrich, M., \& Goguadze, G. (2010). Learning from erroneous examples: when and how do students beneft from them? Sustaining TEL: from innovation to learning and practice (pp. 357-373). Berlin: Springer. https://doi.org/10.1007/978-3-642-16020-2_24

\section{http://www.ejmste.com}

